Landslides (2017) 14:1289-1296 DOI 10.1007/s10346-017-0857-0 Received: 29 June 2017 Accepted: 30 June 2017 Published online: 29 July 2017 c) Springer-Verlag GmbH Germany 2017

\section{Kyoji Sassa}

\section{The 2017 Ljubljana Declaration on landslide risk reduction and the Kyoto 2020 Commitment for global promotion of understanding and reducing landslide disaster risk}

\section{Introduction}

The 4th World Landslide Forum was convened and organized in Ljubljana, Slovenia, from 29 May to 2 June 2017 by the International Consortium on Landslides (ICL), International Programme on Landslides (IPL), University of Ljubljana, and Geological Survey of Slovenia. Six hundred eight participants including scientists, engineers, researchers, policy makers, public officials as well as other stakeholders attended the forum. The event addressed how landslide knowledge, technology, and investigation can be further enhanced and applied to contribute to the reduction of vulnerability and exposure and to building the resilience among persons, communities, and countries to landslide disasters. The forum comprised a High-Level Panel Discussion and roundtable, technical, and poster sessions. The participants valued the mobilization generated by the forum as with previous World Landslide Forums, namely WLF 1 in Tokyo in November 2008, WLF 2 in Rome in October 2011, and WLF 3 in Beijing in June 2014. They recognized, with great satisfaction, the progress made by the ISDR-ICL Sendai Partnerships 2015-2025 for Global Promotion of Understanding and Reducing Landslide Disaster Risk which was adopted as a voluntary commitment to the United Nations World Conference on Disaster Risk Reduction, in Sendai, Japan, 14-18 March 2015 and committed to pursue and support its further implementation. The participants recognized the concrete actions and cooperative activities carried out by the ICL family including through ICL Members, the IPL and IPL Projects, ICL Supporting Organizations, ICL Regional and Thematic Networks, ICL World Centres of Excellence on Landslide Risk Reduction, ICL UNITWIN Cooperation Programme in the framework of the UNITWIN/ UNESCO Chairs Programme, Landslide School Network, Landslide Journal, and other ICL publications. They valued the most recent output which is illustrated by the ISDR-ICL Landslide Interactive Teaching Tools. Notable outcomes of the forum featured at the High-Level Panel Discussion were the 2017 Ljubljana Declaration on Landslide Risk Reduction, furthering of the process leading to the organization of the Fifth World Landslide Forum (WLF 5) in Kyoto, Japan, in 2020 and endorsement of a first outline of the Kyoto 2020 Commitment which will be elaborated and finalized during the preparatory activities for, and adopted at WLF 5. This preface provides highlights of the forum.

The High-Level Panel Discussion and the roundtable discussion The high-level panel discussion: strengthening intergovernmental network and the International Programme on Landslides (IPL) for "ISDR-ICL Sendai Partnerships 2015-2025 for global promotion of understanding and reducing landslide disaster risk" was organized in 13:30-15:45 on 30 May 2017 in Linhart Hall of the Cultural and Congress Centre Ljubljana (Cankarjev dom) (Fig. 1).

Objectives: The International Programme on Landslides (IPL) is a program of the International Consortium on Landslides (ICL). ICL proposed the IPL in a thematic session of the second World Conference on Disaster Reduction (WCDR) in Kobe, 2005. The activities of IPL were defined in the 2006 Tokyo Action Plan "Strengthening research and learning on landslides and related earth system disasters for global risk preparedness" at the roundtable discussion held in Tokyo, 2006. IPL was supported by seven global stakeholders-UNESCO, WMO, FAO, UNISDR, UNU, ICSU, and WFEO; and ICL exchanged an MoU to promote the Tokyo Acton Plan with each of them in 2006.

The activities of IPL include the triennial organization of the World Landslide Forum, implementation of various IPL projects, identification of World Centres of Excellence on Landslide Risk Reduction (WCoE), and publication of the ICL bimonthly journal Landslides. Based on this background, ICL proposed the ISDR-ICL Sendai Partnerships 2015-2025 for global promotion of understanding and reducing landslide disaster risk at the third WCDRR in Sendai, 2015 that was accepted and signed by 17 global and national stakeholders including the governments of Croatia, Italy, and Japan.

This High-Level Panel Discussion aims to strengthen networking with governments in landslide-prone countries and governments supporting landslide disaster risk reduction efforts in developing countries. The close cooperation within governments, United Nations Organizations, and international NGOs is necessary and effective to implement the ISDR-ICL Sendai Partnerships 2015-2025 and the International Programme on Landslides (IPL) as its infrastructure.

Chair: Jakob Rhyner (Vice rector of UNU).

Moderator: Kaoru Takara (ICL Treasurer, Director of Disaster Prevention Research Institute, Kyoto University).

\section{Panelists}

Signatory organizations:

Kyoji Sassa (Executive Director of ICL: proposing and host organization).

Qunli Han (Chair of IPL-Global Promotion Committee, Director of UNESCO Ecological and Earth Sciences).

Andrey Kushlin (Deputy Director of the FAO Forestry Department).

Alasdair Hainsworth (Chief of the WMO DRR Services Division). Irasema Alcantara-Ayala (on behalf of ICSU President, Gordon McBean). 


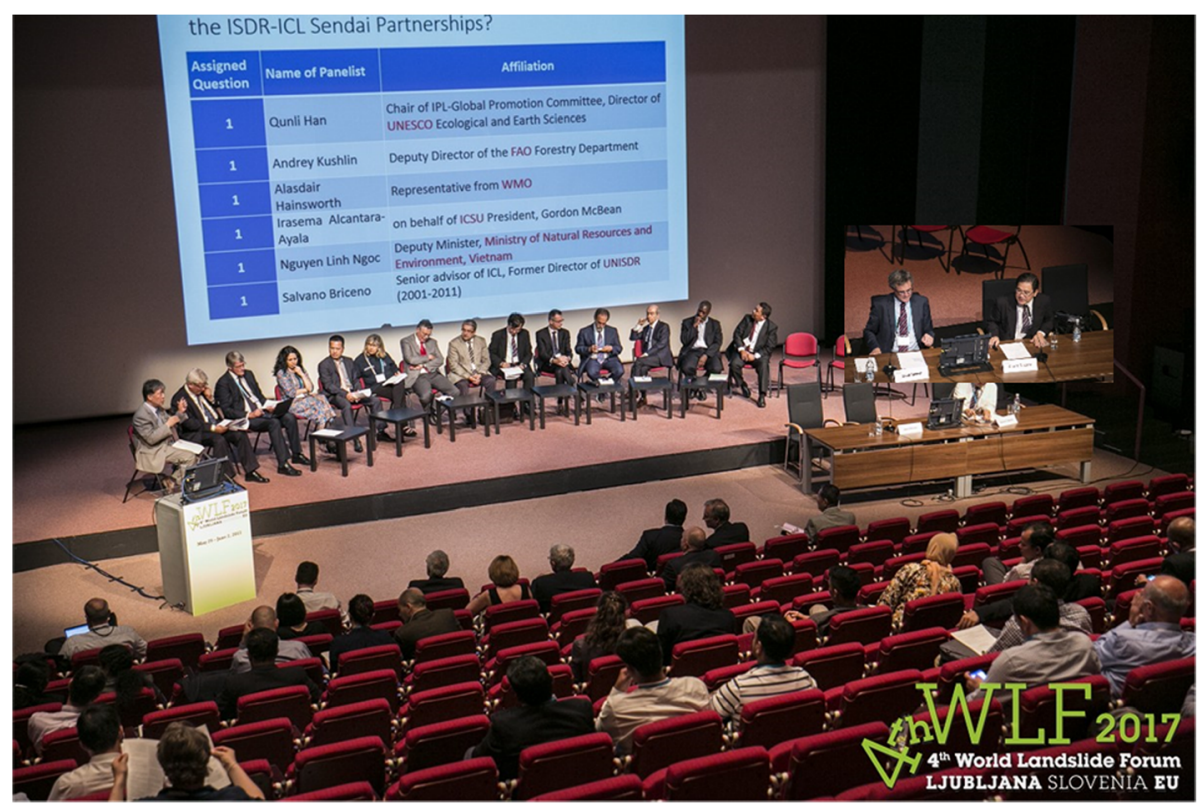

Fig. 1 Photo of panelists on the stage, the chair and the moderator, and participants of the High-Level Panel Discussion on 30 May 2017

Roland Oberhänsli (Former President of IUGS).

Alik Ismail-Zadeh (Secretary General of IUGG).

Satoru Nishikawa (Former director, Disaster Preparedness and International Cooperation, Cabinet office of Japan).

Paola Pagliara (Manager, National Centre for Forecasting and Surveillance for Hydrologic and Hydraulic Risk, Italian Civil Protection Department (DPC)).

Badaoui Rouhban (on behalf of Walter Ammann (President of Global Risk Forum, Davos)).

Additional signatory organizations:

Rudi Phadmanto (Deputy Minster, the Indonesian National Agency for Disaster Management).

Miloš Bizjak (State Secretary, Ministry of Defense, Republic of Slovenia). Hung Le Quoc (on behalf of Nguyen Linh Ngoc (Deputy Minister, Ministry of Natural Resources and Environment, Vietnam)).

Shuaib Lwasa (Chair of the IRDR Science Committee).

Luca Demicheli (Secretary General of EuroGeoSurveys).

An expert from ICL:

Salvano Briceno (ICL senior advisor, Former Director of UNISDR 2001-2011).

The round table discussion as the follow-up of the High-Level Panel Discussion was organized in 13:30-15:00 at Club CD on 31 May 2017. Fig. 2 shows five signatory organizations from the right to the left: Branko Dervodel on behalf of Darko But (Slovenia), Luca Demicheli (EuroGeoSurveys), Rudi Phadmanto (Indonesia), Shuaib Lwasa (IRDR), and Hung Le Quoc on behalf of Nguyen Linh Ngoc (Vietnam).

Summary report of the High-Level Panel Discussion on 30 May 2017 and the round table discussion on 31 May 2017.

The report was compiled by Jakob Rhyner (Chair), Kaoru Takara (Moderator), and Badaoui Rouhban (A panelist and the moderator of the 2015 WCDRR session adopted the Sendai Partnerships 2015-2025).
1. At the 4 th World Landslide Forum, a High-Level Panel Discussion took place in the afternoon of 30 May 2017. The purpose of the discussion was set as to strengthen networking with governments in landslide-prone countries and governments supporting landslide disaster risk reduction efforts in developing countries. The rationale behind focusing the discussion towards this purpose is that close cooperation between and within governments, United Nations organizations, and international nongovernmental organization is necessary and effective to implement and develop further the ISDR-ICL Sendai Partnerships 2015-2025 and the International Programme on Landslides (IPL) as its infrastructure. Hence, the panel discussion was given the following title: Strengthening intergovernmental network and the International Programme on Landslides (IPL) for "ISDR-ICL Sendai Partnerships 2015-2025 for global promotion of understanding and reducing landslide disaster risk".

2. Panelists included representatives and experts from the 17 signatories of the partnerships, government officials from landslide prone countries as well as government officials supporting landslide disaster risk reduction efforts in developing countries.

3. A broad description of ISDR-ICL Sendai Partnerships, of its achievements so far and of the challenges ahead was presented.

4. The discussions revolved around the two following questions:

a. How can we generally advance the implementation of the ISDR-ICL Sendai Partnerships?

b. How do we achieve a better commitment of the partners to the ISDR-ICL Sendai Partnerships, a better networking and interaction to enhance cooperation among partners and to provide substantive services to developing countries? 


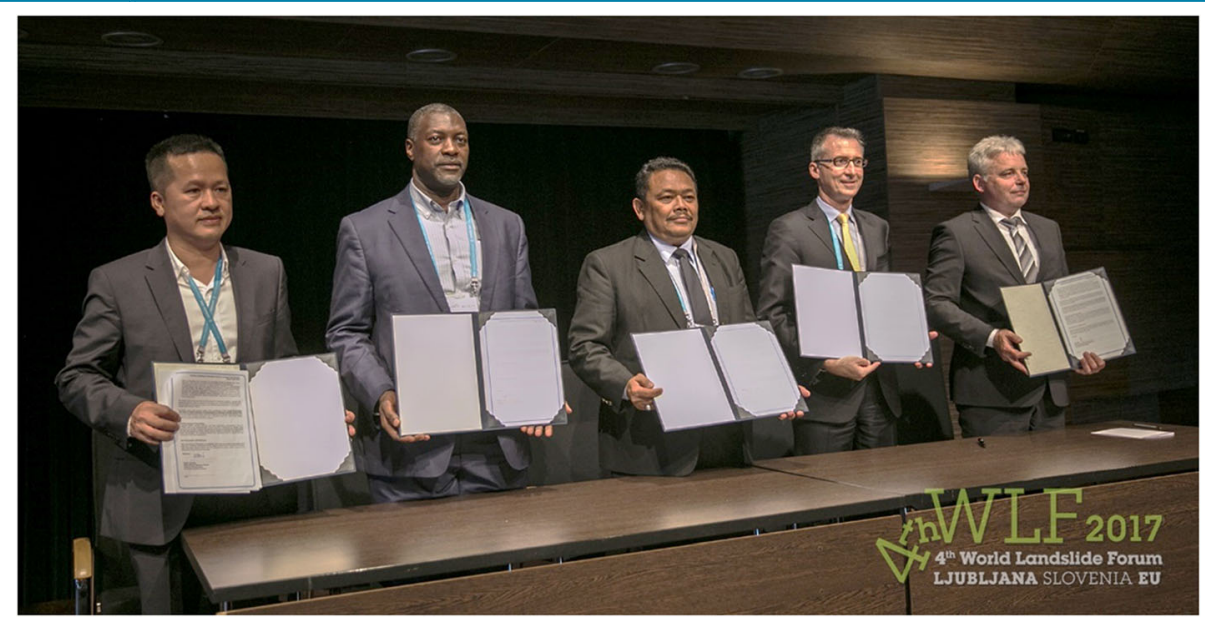

Fig. 2 Additional signatories of the ISDR-ICL Sendai Partnerships 2015-2025 in Ljubljana, Slovenia on 31 May 2017

5. The discussion recognized that, since its establishment in March 2015, the ISDR-ICL Sendai Partnerships is making smooth progress. The commitment by a number of partners has enabled the partnerships to make significant achievements in such a short period of time. More interaction among partners would help further, through, for instance, bilateral cooperative modalities. Above all, the partnerships should mobilize further, at the local level, institutions, and individuals who are already active in, or familiar with ICL, and provide them with tools and conditions to enable them to act locally. Local "champions" are needed.

6. Partners voiced commitments (i) to enable the engagement in the partnerships and take a lead on different aspects of its implementation, (ii) to work together with other partners on relevant co-operative fields, and (iii) to offer expertise in cooperating with developing countries. A call was made to make clear the roles and responsibilities of each partner.

7. Fundamental actions for ICL would involve a commitment of all partners in preparedness, particularly by enhancing communicating science, promoting education on DRR for the new generation of stakeholders, and enhancing collaboration between decision makers and the scientific community; this must include the fact that managing the territory on an integrated basis becomes an urgent challenge to reduce landslide disaster risk. The establishment of practice oriented scientific networks on landslides is also highly desirable.

8. To advance in the implementation of the ISDR-ICL Sendai Partnerships, there must be a common understanding on the way societies construct disaster risk so that we can prevent new and reduce existing disaster risk. Therefore, vulnerability patterns should be properly recognized, and efforts must be aligned with sustainable practices so that disaster risk drivers are reduced and root causes of disasters are addressed in the best possible way.

9. There is a clear need to move from mono/multi-disciplinary approaches towards integrated disaster research, that is to say, a trans/inter disciplinary perspective, aiming at the coproduction of knowledge as an iterative societal process to achieve disaster risk reduction.
10. A few specific objectives, such as warning systems and spatial planning, could be determined, on which all partners can work together in an interdisciplinary and perhaps even transdisciplinary manner, all contributing to the implementation of the Sendai Partnerships on landslide disaster risk reduction.

11. With the aim of reducing deaths and losses related to landslides, according to the Sendai Framework for Disaster Risk Reduction (SFDRR), by 2025, a set of products could be identified with the purpose of impacting on the way that governments, communities, and the public relate to landslides and, in consequence, modify their behavior thus achieving the paradigm shift that the ISDR implies. In particular:

i. A set of policy guidelines for reducing and managing risk related to landslides, to distribute to governments, addressing policy, legislative, organizational, and research requirements for effectively reducing vulnerabilities and risk related to landslides, to be applied from local to national levels;

ii. A set of interactive learning tools on landslide risk reduction, for dissemination to schools, community-based organizations, NGOs, at all levels, from primary to university, with a view to facilitating work at the community and educational levels;

iii. A set of awareness-raising messages to reduce vulnerability to landslides, to disseminate to media around the world to address the general public, including the social media and Internet.

12. A strategic plan should be formulated including elements such as (a) producing materials in as many languages as possible; (b) disseminating them through partners' networks, including those of UNISDR, UNESCO, WMO, FAO, UNDP, UNEP, UNU, ICSU/ISSC, World Bank's GFDRR, GNDR, IRDR, WFEO, IUGS, IUGG, and so on; and (c) identifying a first group of most vulnerable countries and com munities to start with and gradually expanding to cover more countries around the world. 
13. Whereas big disasters with its impact and losses make the headlines, success stories wherein preventing and mitigating disaster losses have occurred but rarely make the headlines. Thus ICL should work towards a better recognition of preventive efforts by the general public!

14. Landslide disasters depend on the local geography and local land use. Landslide experts go to the sites and work on the ground and interact with the locals. The time has come to highlight success stories, highlight success of landslide disaster prevention/mitigation, and highlight cases where good dialogue between the scientists and local leaders enabled proper land use control, early warning, and evacuation, thus avoiding fatalities. Local mayors should be encouraged to speak about such cases. The landslide scientist and the local mayor must be encouraged to co-author publications, both in English and the local language, for newspapers or for the landslide journal.

15. Disaster risk reduction must be carried out at local level, including through inclusive and integrated approaches. Furthermore, traditional and native knowledge should be incorporated into the scientific strategies. Integrated management of the territory, including development and sustainable practices are the key elements to reduce landslide disaster risk, and hence constitutes a challenge for the successful implementation of the ISDR-ICL Sendai Partnerships.

16. Whereas in some instances, significant progress and achievements are made at the national level in landslide disaster risk assessment, difficulties are encountered in transferring scientific knowledge to local government and local people, who are poor and less educated. There is likewise a lack of experienced people in implementing projects at the local level. Therefore, Sendai Partnerships can offer help by sharing expertise among partners to transfer scientific knowledge to local people, to look at landslide science such as triggering factors, and to find better measures for landslide hazard mitigation and risk reduction such as early warning systems, specifically for places where landslides often occur with other disasters such as flash floods.

17. A major challenge remains in the line of education in the sense of geogovernance by training socio-economic as well as political administrative decision makers in a better understanding of foreseeable but unpredictable geodynamic processes. Another overriding challenge is the spread of a culture of civil protection in a people-centered perspective.

18. Commitment is "action" and to get action, partners to the ISDRICL partnership would require more engagement and networking. One strategy that could have promise of this commitment is the regionalization of the landslide fora and the partners in conjunction with the ICL-World Centres of Excellence could take the lead. This would enhance the cooperation.

19. While developing countries clearly need services, there is also need to recognize the capacities in developing countries. There is so much to learn in developing countries as there is elsewhere that cooperation should be on equal or equitable terms. Likewise, there are scientists and researchers based, and working in developing countries, there is need to work with them more than providing them and their governments "services".

20. There is a need to be careful about creating new risk or accentuating risk in situations of resettlement and relocation in the aftermath of disasters.
21. Partners need to consider providing periodic assessment of disasters to directly feed into the UNISDR implementation processes of the SFDRR, also in line with the outcome of the Science and Technology Advisory Group in Geneva in 2016 in the road map for S\&T group in the implementation of SFDRR.

22. The "2017 Ljubljana Declaration on Landslide Risk Reduction-contributing to the Sendai Framework for Disaster Risk Reduction-was introduced and its draft presented. The chairperson of the panel discussion underlined and welcomed the expected adoption of this declaration later on in the forum.

23. Ongoing plans for organizing the next World Landslide Forum, that is the upcoming World Landslide Forum 5 to be hosted in Kyoto, in November 2020 and texts introducing the concept of "Kyoto 2020 Commitment of the World Landslide Community" were presented. The chairperson of the panel discussion underlined and welcomed the expected endorsement of the plans and of the concept of a Kyoto 2020 Commitment later on in the forum.

24. At the roundtable discussion: Review of $\mathrm{WLF}_{4}$ and forum development towards WLF5 which took place on 31 May 2017, the 2017 Ljubljana Declaration on Landslide Risk Reduction was adopted, and the plans for the World Landslide Forum 5 and the outline on the concept of the "Kyoto 2020 Commitment" were endorsed.

\section{Ljubljana Declaration on Landslide Risk Reduction:}

Contributing to the Sendai Framework for Disaster Risk Reduction

1. The World Landslide Forum IV was convened and organized in Ljubljana, Slovenia, from 29 May to 2 June 2017 by the International Consortium on Landslides (ICL), International Programme on Landslides (IPL), University of Ljubljana, and Geological Survey of Slovenia. The event was co-organized by the Ministry of Defense, Ministry of the Environment and Spatial Planning, Ministry of Infrastructure, National Platform for Disaster Risk Reduction, and Chamber of Engineers of the Republic of Slovenia. The forum was sponsored by several other entities. Six hundred eight participants* including scientists, engineers, researchers, policy makers, public officials as well as other stakeholders came from 49 countries/regions, four United Nations organizations, and five other international organizations.

2. The participants appreciate the hospitality and welcome that was accorded to the forum by the authorities and relevant institutions of Slovenia.

3. The participants addressed the challenges of landslide disaster risk. They examined how landslide knowledge and technology and landslide investigation can be further enhanced and applied to contribute to the reduction of vulnerability and exposure and to building the resilience of persons, communities, and countries to landslide disasters which, like other disasters triggered by natural hazards, undermine efforts to achieve the Sustainable Development Goals (SDGs) of the 2030 Agenda for Sustainable Development.

4. The participants note that landslides are a complex natural phenomenon of many types and varieties that can be triggered by earthquakes, volcanic eruptions, heavy and recurrent rainfall, typhoons, hurricanes, wildfires, snowmelt and sometimes 
exacerbated by anthropogenic activities and developments such as construction of roads, waterworks, and mining. They recall that submarine landslides are able to generate tsunamis and represent a major hazard to coastal areas.

5. The participants underline that landslides, occurring on land and at sea, continue to pose considerable risks to humankind, to human settlements, and to livelihoods and economies in mountains, cities, along coasts, and islands. They underline further that people most exposed to, and affected by landslide disasters, are disproportionately the poor, marginalized and vulnerable, including women and children.

6. The participants caution that climate change and variability are expected to increasingly affect the frequency and extent of heavy rainfall and wildfires at local and regional levels with an enhanced potential for landslide occurrence. They recognize that the combined effects of natural phenomena and human adverse activities, associated with a rise in the vulnerability and exposure of urban and rural settlements and agglomerations, are increasing landslide risk around the world.

7. The participants reiterate that understanding landslides, their associated risks and the vulnerability of societies, requires an integrated and multi-disciplinary approach including contributions from natural, social, and engineering sciences as well as local and traditional knowledge.

8. The participants value the mobilization generated and the significant impact of activities developed and implemented throughout the processes of previous World Landslide Forums, namely WLF 1 held in Tokyo in November 2008, WLF 2 held in Rome in October 2011, and WLF 3 held in Beijing in June 2014.

9. The participants recognize and welcome, in particular, the ISDR-ICL Sendai Partnerships 2015-2025 for Global Promotion of Understanding and Reducing Landslide Disaster Risk which was adopted as a voluntary commitment to the United Nations World Conference on Disaster Risk Reduction, held in Sendai, Japan, 14-18 March 2015. They affirm that this partnership is a supporting tool for the implementation of the Sendai Framework for Disaster Risk Reduction 20152030. They greet and commend the numerous partners who adhered to this partnership. They recognize, with great satisfaction, the progress made by the partnerships during the first biennium of its life. They commit to pursue and support its further implementation, including through building on the 2012 ICL Strategic Plan 2012-2021.

10. The participants recognize the concrete actions and cooperative activities carried out by the ICL family including through ICL Members, the IPL and IPL Projects, ICL Supporting Organizations, ICL Regional and Thematic Networks, ICL World Centres of Excellence on Landslide Risk Reduction, ICL UNITWIN Cooperation Programme in the framework of the UNITWIN/UNESCO Chairs Programme, Landslide School Network, Landslide Journal, and other ICL publications. They value the most recent output which is illustrated by the ISDR-ICL Landslide Interactive Teaching Tools.

11. The participants reiterate their call upon related governmental, non-governmental, and international programs, and initiatives from natural, engineering, human, social and economic sciences, public and private, to continue promoting science and technology and their applications for landslide disaster risk mitigation including by supporting and joining the ISDR-ICL Sendai Partnerships.

12. The participants look forward to the initiation and furthering of the process leading to the organization of the Fifth World Landslide Forum (WLF 5) in 2020.

13. The participants view that, in the perspective of, and during the WLF 5, an opportunity must be found to mobilize in the medium and long term a global alliance which will accelerate and incentivize action for landslide risk reduction. They therefore urge to put in place a mechanism to that effect and call for a commitment, the Kyoto 2020 Commitment for Global Promotion of Understanding and Reducing Landslide Disaster Risk, to be finalized during the preparatory activities for WLF 5 and adopted during WLF 5 in order to serve this purpose.

14. The participants express gratitude to governmental authorities and specialized organizations and entities worldwide, and in particular authorities and organizations from Japan, for the valuable support which they provide to ICL-IPL. They express sincere appreciation to the leadership and management of ICL for their dedication to the functioning of the consortium and to the continuation of its initiatives and activities.

15. The participants submit the 2017 Ljubljana Declaration on Landslide Risk Reduction to UNISDR for endorsement as a further commitment on the part of the global landslide community to the Sendai Framework for Disaster Risk Reduction 2015-2030.

Adopted in Ljubljana on 31 May 2017.

Note: The ANNEX to the 2017 Ljubljana Declaration on Landslide Risk Reduction is found in ICL/IPL Activities in this issue.

\section{The Concept of the Kyoto 2020 Commitment-Call for participating parties}

The concept note of the Kyoto 2020 Commitment for global promotion of understanding and reducing landslide disaster risk was presented at the High-Level Panel Discussion held on 30 May 2017. It was agreed at the conclusion of the round table discussion which took place on 31 May 2017 as a follow-up to the High-Level Panel Discussion. The basic concept of the Kyoto 2020 Commitment is to create a long-term, wider, and stronger framework for the global landslide risk reduction network. The call for participating parties into the Kyoto 2020 Commitment was also endorsed as part of the concept. The timeline for the Kyoto 2020 Commitment process is shown in Fig. 3.

As indicated in Fig. 3, the first presentation and examination of the concept were carried out at the WLF4 in Ljubljana, Slovenia and the process of the follow-up is now being pursued. The next milestone in the process will occur at the meeting of the first group of parties which will be held at UNESCO Headquarters, Paris on 29 November to 1 December 2017. At that meeting, the outline of the Kyoto 2020 Commitment will be produced. The third step is to establish a draft of the Kyoto Commitment to be implemented at the beginning of November 2018 at the venue of WLF5, the Kyoto International Conference Hall, Kyoto, Japan. A fourth milestone date will be November 2019 at the ICL-IPL meeting at UNESCO, Headquarters, Paris. The fifth and the final step will be the agreement of the Kyoto 2020 Commitment and signatures by all 


\begin{tabular}{|lcccc|}
\hline $\begin{array}{l}\text { WLF4 } \\
\text { Ljubljana }\end{array}$ & $\begin{array}{c}\text { ICL-IPL Meeting } \\
\text { UNESCO, Paris } \\
5-6 / 2017\end{array}$ & $\begin{array}{c}\text { ICL-IPL Meeting } \\
\text { KICC, Kyoto } \\
11 / 2017\end{array}$ & $\begin{array}{c}\text { ICL-IPL Meeting } \\
\text { UNESCO, Paris }\end{array}$ & $\begin{array}{c}\text { WLF5 } \\
\text { KICC, Kyoto } \\
11 / 2020\end{array}$ \\
\hline $\begin{array}{l}\text { Concept note: } \\
\text { Call for } \\
\text { participating } \\
\text { parties }\end{array}$ & $\begin{array}{l}\text { Outline by the first } \\
\text { group of parties }\end{array}$ & $\begin{array}{l}\text { Draft of Kyoto } \\
\text { Commitment } \\
\text { by an enlarged } \\
\text { group of parties }\end{array}$ & $\begin{array}{l}\text { Agreed Draft } \\
\text { of Kyoto } \\
\text { Commitment } \\
\text { by parties }\end{array}$ & $\begin{array}{l}\text { Final } \\
\text { Commitment } \\
\text { and Signature } \\
\text { by all parties }\end{array}$ \\
\hline
\end{tabular}

Fig. 3 Timeline for the Kyoto 2020 Commitment process

participating parties during the Fifth World Landslide Forum at the Kyoto International Conference in Kyoto, Japan.

With the adoption of the ISDR-ICL Sendai Partnerships (SP) 2015-2025, the ICL community has achieved a major step in reaching a framework for Landslide Disaster Risk Reduction. The implementation of the SP has been recognized at the WLF4. The Ljubljana Declaration acknowledges progress made in this implementation. It also recognizes the process initiated to prepare for the WLF5. A concept for a mechanism to be put in place at WLF5, the concept of "Kyoto 2020 commitment for global promotion of understanding and reducing landslide disaster risk", was approved during the WLF4. Building on this step, work is currently under way to develop the text of the Kyoto 2020 Commitment which, until considered and approved at $\mathrm{WLF}_{5}$ in November 2020, will be a living document, or a work in progress.

The current concept note (30 June 2017) of the Kyoto 2020 Commitment is shown as follows.

Kyoto 2020 commitment for global promotion of understanding and reducing landslide disaster risk.

To the ISDR-ICL Sendai Partnerships 2015-2025, the Sendai Framework for Disaster Risk Reduction 2015-2030 and the 2030 AgendaSustainable Development Goals.

Landslide disasters are caused by exposure to hazardous motions of soil and rock that threaten vulnerable human settlements in mountains, cities, along river banks, coasts, and islands. An increase in the frequency and/or magnitude of heavy rainfall, and shifts in the location, and periodicity of this rainfall due to changing climate may significantly intensify the risk of landslides in some landslide prone areas.

Developments in mountains and coastal areas, including construction of roads and railways, expansion of urban areas, and deforestation due to population growth and movement increase exposure to the hazards of landslides. Landslide disaster risk reduction is a globally important objective in all countries/ regions where people living in mountains and slopes are exposed to landslides.

The International Consortium on Landslides (ICL) proposed the Sendai Partnerships 2015-2025 for Global Promotion of Understanding and Reducing Landslide Disaster Risk in the Working Session "Underlying Risk Factors" during the third World
Conference on Disaster Risk Reduction (WCDRR) in Sendai, Japan. The Sendai Partnerships was adopted and signed by 17 United Nations and international and national stakeholders. Joint efforts thereafter have been made and resulted in the edition and publication of the open access full color book "ISDR-ICL Sendai Partnerships 2015-2025," Vol.1 of the Fourth World Landslide Forum, the edition of "Landslide Dynamics: ISDR-ICL Landslide Interactive Teaching Tools", as well as the enhanced publication of the bimonthly full-color journal Landslides: Journal of the International Consortium on Landslides.

The landslide risk to human settlements in mountainous and coastal areas due to landslide motion and landslide-induced tsunamis in many countries will likely continue to rise even after the latter-half period of the Sendai Partnerships 2015-2025. In September 2015, the United Nations General Assembly adopted the 2030 Agenda including Goal 11 to make cities and human settlements inclusive, safe, resilient, and sustainable. As a voluntary commitment to the 2030 Agenda and to the Sendai Framework for Disaster Risk Reduction 2015-2030, participants in the Fourth World Landslide Forum considered and further endorsed the first outline of the Kyoto 2020 Commitment as a stable global framework to mobilize in the medium and long term a global alliance which will accelerate and incentivize action for landslide disaster risk reduction.

The High-Level Panel Discussion on "Strengthening Intergovernmental Network and the International Programme on Landslides (IPL) for "ISDR-ICL Sendai Partnerships 2015-2025 for global promotion of understanding and reducing landslide disaster risk" was organized during the Fourth World Landslide Forum in Ljubljana on 30 May 2017.

The panelists were from the signatory organizations of Sendai Partnerships (ICL, UNESCO, WMO, FAO, UNU, ICSU, WFEO, IUGS, IUGG, Cabinet Office of Japan, Italian Civil Protection, Global Risk Forum, and Davos) and new signatory organizations (the Indonesian National Agency for Disaster Management, Ministry of Defense, Republic of Slovenia, Ministry of Natural Resources and Environment, Vietnam, IRDR Science Committee, and EuroGeoSurveys) as well as experts in this field.

The outcome of this High-Level Panel Discussion was reviewed by the Round Table Discussion to promote the Sendai Partnerships and the participants approved the 2017 Ljubljana Declaration on Landslide Risk Reduction. The declaration endorsed the plan for the organization of the Fifth World Landslide Forum in Kyoto, 
Japan in November 2020 and the preparation of the Kyoto 2020 Commitment of a global alliance which aims, in the medium and long term, to accelerate and incentivize action for landslide disaster risk reduction to 2025,2030 , and beyond.

The Kyoto 2020 Commitment is expected to reaffirm the following resolution of the Sendai Partnerships, acknowledging that

- Landslide disasters are caused by exposure to hazardous motions of soil and rock that threaten vulnerable human settlements in mountains, cities, coasts, and islands.

- Climate change will intensify the risk of landslides in some landslide prone areas through an increase in the frequency and/or magnitude of heavy rainfall, and shifts in the location and periodicity of heavy rainfall.

- Developments in mountains and coastal areas, including construction of roads and railways and expansion of urban areas due to population shifts, increase exposure to hazards of landslides.

- Although they are not frequent, strong earthquakes have potential to trigger rapid and long runout landslides and liquefaction. Earthquake-induced coastal or submarine large-scale landslides or megaslides (with depths on the order of hundreds of meters to $1000 \mathrm{~m}$ ) in the ocean floor can trigger large tsunami waves. These hazardous motions of soil and water impacting on exposed and vulnerable population can result into very damaging effects.

- The combined effects of triggering factors, including rainfall, earthquakes, and volcanic eruptions, can lead to greater impacts through disastrous landslides such as lahars, debris flows, rock falls, and megaslides.

- Understanding landslide disaster risk requires a multi-hazard approach and a focus on social and institutional vulnerability. The study of social and institutional as well as physical vulnerability is needed to assess the extent and magnitude of landslide disasters and to guide formulation of effective policy responses.

- Human intervention can make a greater impact on exposure and vulnerability through, among other factors, land use and urban planning, building codes, risk assessments, early warning systems, legal and policy development, integrated research, insurance, and, above all, substantive educational and awareness-raising efforts by relevant stakeholders.

- The understanding of landslide disaster risk, including risk identification, vulnerability assessment, time prediction, and disaster assessment, using the most up-to-date and advanced knowledge, is a challenging task. The effectiveness of landslide disaster risk reduction measures depends on scientific and technological developments for understanding disaster risk (natural hazards or events and social vulnerability), political "buy-in," and on increased public awareness and education.

- At a higher level, social and financial investment is vital for understanding and reducing landslide disaster risk, in particular, social and institutional vulnerability through coordination of policies, planning, research, capacity development, and the production of publications and tools that are accessible, available free of charge and are easy to use for everyone in both developing and developed countries.

We agree on the following initial fields of cooperation in research and capacity building, coupled with social and financial investment:
- Development of people-centered early warning technology for landslides with increased precision and reliable prediction both in time and location, especially in a changing climate context.

- Development of hazard and vulnerability mapping, vulnerability and risk assessment with increased precision, and reliability as part of multi-hazard risk identification and management.

- Development of improved technologies for monitoring, testing, analyzing, simulating, and effective early warning for landslides.

- Development of international teaching tools that are always updated and may be used free of charge by national and local leaders and practitioners, in developed and developing countries through the Sendai Partnerships 2015-2025.

- Open communication with society through integrated research, capacity building, knowledge transfer, awareness-raising, training, and educational activities to enable societies to develop effective policies and strategies for reducing landslide disaster risk, to strengthen their capacities for preventing hazards to develop into major disasters, and to enhance the effectiveness and efficiency of relief programs.

- Development of new initiatives to study research frontiers in understanding landslide disaster risk, such as the effect of climate change on large-scale landslides and debris flows, the effective prediction of localized rainfall to provide earlier warning and evacuation especially in developing countries, the mechanism and dynamics of submarine landslides during earthquakes that may cause or enhance tsunamis, and geotechnical studies of catastrophic megaslides for prediction and hazard assessment.

Further to the above resolution, the Kyoto 2020 Commitment also agrees that the following activities are carried out in order to develop a wider and long-term global alliance for landslide risk reduction:

- Kyoto 2020 Commitment integrates the ISDR-ICL Sendai Partnerships signatory organizations, ICL members and ICL supporters.

- ICL associates defined in Ljubljana 2017 and other international, national governmental, and non-governmental organizations, municipalities, local communities, and private sectors are invited to take action for landslide disaster risk reduction and contribute to "the Kyoto 2020 Commitment."

- Landslide experts must gain trust and confidence from the local authorities and the communities facing the risk of landslides in order to duly communicate the risk and urge local actions to reduce the risk, thus good dialogue at local levels is indispensable throughout the activities of Kyoto 2020 Commitment.

- Emphasis will be put on sharing real experiences of good scientific communication by landslide experts with local authorities and communities that lead to preventive action on the ground.

- The progress and achievements made by the parties of the Commitment in the category of ICL/IPL activities will be published in the monthly* full-color Journal "Landslides" (*plan to shift from bimonthly to monthly before 2020).

- All parties of the Kyoto 2020 Commitment have the right to submit and publish news and reports of their activities in this 
monthly full color journal. All parties will receive the print copy and digital access rights (tokens) to all issues of journal (2002-present) as the common platform.

- The Triannual Conference "World Landslide Forum" will be organized and the progress of Kyoto 2020 Commitment will be reported upon therein.

- To promote cooperation between policy makers and landslide scientists and engineers, national government authorities working on landslide risk reduction, a joint round table discussion between ICL members and the high-level ministerial members will be organized at each forum.

- Community safeguard policy for the countries/areas which are affected by rain-induced rapid and long-travel landslides, earthquake-induced megaslides, and coastal and submarine landslides will be examined in specific sessions in the forum.

- The Kyoto 2020 Commitment parties will further publish Landslide Dynamics-Landslide Interactive Teaching Tools (LITT) as a core activity for public education at each forum as was the case concerning two volumes of text of LITT which were edited and published including PPT for lessons and PDF for reference in 2017, on the occasion of WLF4.

- The Kyoto 2020 Commitment will organize a research, administrative and strategic review conference between the forums at UNESCO, UNISDR, IRDR, as well as at the biennial Global Platform for Disaster Risk Reduction

\section{Host organization and secretariat}

The International Consortium on Landslides (ICL) hosts the Kyoto 2020 Commitment for Understanding and Reducing Landslide Disaster Risk as a voluntary commitment to the United Nations International Strategy for Disaster Reduction. The ICL Secretariat in Kyoto, Japan, serves as the Secretariat of the Sendai Partnerships and of the Kyoto 2020 Commitment.

The concept of the Kyoto 2020 Commitment for global promotion of understanding and reducing landslide disaster risk is based on the development of the past ICL and IPL activities as presented in the following references (Sassa 2006, 2012, 2015, 2017a, 2017b).

References

Sassa K (2006) "2006 Tokyo action plan"- -strengthening research and learning on landslides and related earth system disasters for global risk preparedness. Landslides 3(4):361-369

Sassa K (2012) ICL strategic plan 2012-2021 to create a safer geoenvironment. Landslides $9(2): 155-164$

Sassa K (2015) ISDR-ICL Sendai Partnerships 2015-2025 for global promotion of understanding and reducing landslide disaster risk. Landslides 12(4):631-640

Sassa K (2017a) The fifth world landslide forum-implementing and monitoring the ISDRICL Sendai Partnerships 2015-2025. Landslides 14(3):1282-1288

Sassa, K (2017b) Participants in the Fourth World Landslide Forum and Call for ICL Members, Supporters, and Associates. Landslides, Vol.14 (4)

K. Sassa $(\bowtie)$

International Consortium on Landslides (ICL),

Kyoto, Japan

e-mail: secretariat@iclhq.org 